\title{
Use of Ticagrelor in the Treatment of Acute Coronary Syndromes
}

\section{Wilbert S Aronow*}

Department of Medicine, Divisions of Cardiology, Geriatrics and Pulmonary/Critical Care, New York Medical College, Valhalla, New York, USA

Ticagrelor is a non-thienopyridine antiplatelet drug which is an oral, reversible, direct-acting inhibitor of the ADP receptor P2Y12 [1]. Plasma levels of ticagrelor peak rapidly 1.5 to 3.0 hours after administration with antiplatelet effects occurring within 2 hours after administration. Ticagrelor has a half life of 7 to 8.5 hours with the metabolite lasting up to 12 hours [2]. This combined with its reversible binding to the ADP receptor P2Y12 requires twice daily dosing [2]. The rapid reversibility is beneficial if a surgical procedure has to be performed but is a disadvantage in poorly compliant patients. A loading dose of ticagrelor $180 \mathrm{mg}$ achieves faster and greater platelet inhibition than a $600 \mathrm{mg}$ loading dose of clopidogrel and is faster in offset after drug discontinuation than is clopidogrel [3].

In the Study of Platelet Inhibition and Patient Outcomes (PLATO), 18,624 patients hospitalized with an acute coronary syndrome with or without ST-segment elevation were randomized in a double-blind trial to aspirin (98\%) plus either ticagrelor (180 mg loading dose followed by $90 \mathrm{mg}$ twice daily) or clopidogrel (300 $\mathrm{mg}$ to $600 \mathrm{mg}$ loading dose followed by $75 \mathrm{mg}$ daily) [4]. At 12- month follow-up, the primary endpoint of cardiovascular death, nonfatal myocardial infarction, or nonfatal stroke was significantly reduced from $11.7 \%$ in patients treated with clopidogrel to $9.8 \%$ in patients treated with ticagrelor, a relative risk reduction of $16 \%$ and an absolute risk decrease of $1.9 \%$. The number of patients needed to treat to prevent 1 event $=53$ [4]. The incidence of all-cause mortality was significantly reduced from $5.9 \%$ in patients treated with clopidogrel to $4.5 \%$ in patients treated with ticagrelor, a relative risk reduction of $24 \%$ and an absolute risk decrease of $1.4 \%$. The number of patients needed to treat to prevent 1 death $=71$ [4]. No significant difference in major bleeding was found between both groups. However, the incidence of major bleeding not related to coronary artery bypass graft surgery was significantly higher on ticagrelor $(4.5 \%)$ than on clopidogrel $(3.8 \%)$. Fatal intracranial bleeding occurred significantly more in patients treated with ticagrelor $(0.1 \%)$ than in patients treated with clopidogrel (0.01\%) [4]. Dyspnea requiring discontinuation of study treatment occurred significantly more in patients treated with ticagrelor $(0.9 \%)$ than in patients treated with clopidogrel (0.1\%) [4].

However, there was an insignificant $27 \%$ increase in the primary outcome in patients treated with ticagrelor versus clopidogrel in the United States and Canadian patients [5]. Ticagrelor was approved by the United States Food and Drug Administration for treatment of patients with acute coronary syndromes with the maintenance dose of aspirin to be 75 to $100 \mathrm{mg}$ daily.

In the PLATO study, an invasive strategy was planned for 13,408 of the 18,624 patients (72\%) hospitalized for acute coronary syndromes [6]. At 360-day follow-up of these patients, the primary endpoint of cardiovascular death, nonfatal myocardial infarction, or nonfatal stroke was significantly reduced from $10.7 \%$ in patients treated with clopidogrel to $9.0 \%$ in patients treated with ticagrelor, a relative risk reduction of $16 \%$ and an absolute risk decrease of $1.7 \%$. The number of patients needed to treat to prevent 1 event $=59$ with no significant difference in major bleeding or severe bleeding between both groups [6].

In the PLATO study, in the subgroup of 1,261 patients who underwent coronary artery bypass graft surgery and were receiving study drug treatment less than 7 days before surgery, the primary endpoint at 12 months was significantly reduced from $13.1 \%$ in patients treated with clopidogrel to $10.6 \%$ in patients treated with ticagrelor, a relative risk reduction of $16 \%$ and an absolute risk decrease of $2.5 \%$ [7]. The number of patients needed to treat to prevent 1 event $=40$ with no significant difference in coronary artery bypass graft surgery-related major bleeding between the 2 groups [7]. All-cause mortality was significantly reduced from $9.7 \%$ in patients treated with clopidogrel to $4.7 \%$ in patients treated with ticagrelor, a relative risk reduction of $51 \%$ and an absolute risk decrease of 5.0\%. The number of patients needed to treat to prevent 1 death $=20$ [7].

In the PLATO trial, chronic kidney disease was present in 3,237 patients [8]. In patients with chronic kidney disease, the primary outcome was significantly reduced from $22.0 \%$ in patients treated with clopidogrel to $17.3 \%$ in patients treated with ticagrelor, a relative risk reduction of $23 \%$ and an absolute risk decrease of $4.7 \%$. The number of patients needed to treat to prevent 1 event $=21$ [8]. All-cause mortality in patients with chronic kidney disease was significantly reduced from $14.0 \%$ in patients treated with clopidogrel to $10.0 \%$ in patients treated with ticagrelor, a relative risk reduction of $28 \%$ and an absolute risk decrease of $4.0 \%$. The number of patients needed to treat to prevent 1 death=25 [8]. Major bleeding, fatal bleeding, and non-coronary bypass-related major bleeding were not significantly different between both groups [8]. In patients with normal renal function, the primary outcome was insignificantly reduced $10 \%$ from $8.9 \%$ to $7.9 \%$ by ticagrelor [8].

Ticagrelor therapy overcomes nonresponsiveness to inhibition of platelet aggregation by clopidogrel [9]. The antiplatelet effect of ticagrelor is similar in clopidogrel responders and nonresponders [9]. In the Plato trial, 4,662 patients had diabetes mellitus [10]. In patients with diabetes mellitus, compared with clopiodogrel, ticagrelor insignificantly reduced the primary outcome $12 \%$, all-cause mortality $18 \%$, and stent thrombosis $35 \%$ [10]. However, in patients with a hemoglobin Alc above $6.0 \%$ (the median value), compared with clopidogrel, ticagrelor significantly reduced the primary endpoint $20 \%$, all-cause mortality $22 \%$, and stent thrombosis $38 \%$ [10]. The clinical benefit of ticagrelor compared with clopidogrel was not significantly different between patients aged 75 years and older versus those younger than 75 years [11].

Contraindications to ticagrelor include a history of intracranial

*Corresponding author: Wilbert S. Aronow, Professor of Medicine, Cardiology Division, New York Medical College, Macy Pavilion, Room 138, Valhalla, NY 10595, USA, Tel: 914-493-5311; Fax: 914-235-6274; E-mail: wsaronow@aol.com

Received August 29, 2013; Accepted August August 29, 2013; Published September 04, 2013

Citation: Aronow WS (2013) Use of Ticagrelor in the Treatment of Acute Coronary Syndromes. Cardiol Pharmacol 2: e116. doi:10.4172/2329-6607.1000e116

Copyright: (c) 2013 Aronow WS. This is an open-access article distributed under the terms of the Creative Commons Attribution License, which permits unrestricted use, distribution, and reproduction in any medium, provided the original author and source are credited. 
Citation: Aronow WS (2013) Use of Ticagrelor in the Treatment of Acute Coronary Syndromes. Cardiol Pharmacol 2: e116. doi:10.4172/2329$6607.1000 \mathrm{e} 116$

hemorrhage, active pathological bleeding, severe hepatic impairment, and hypersensitiviy to ticagrelor or any component of the product. Ticagrelor should not be used in patients planned to undergo urgent coronary artery bypass graft surgery. When possible, ticagrelor should be stopped at least 5 days prior to any surgery.

\section{References}

1. Husted S, Emanuelsson H, Heptinstall S, Sandset PM, Wickens M, et al. (2006) Pharmacodynamics, pharmacokinetics, and safety of the oral reversible P2Y12 antagonist AZD6140 with aspirin in patients with atherosclerosis: a doubleblind comparison to clopidogrel with aspirin. Eur Heart J 27: 1038-1047.

2. Nawarskas JJ, Clark SM (2011) Ticagrelor: a novel reversible oral antiplatelet agent. Cardiol Rev 19: 95-100.

3. Gurbel PA, Bliden KP, Butler K, Tantry US, Gesheff T, et al. (2009) Randomized double-blind assessment of the ONSET and OFFSET of the antiplatelet effects of ticagrelor versus clopidogrel in patients with stable coronary artery disease: the ONSET/OFFSET study. Circulation 120: 2577-2585.

4. Wallentin L, Becker RC, Budaj A, Cannon CP, Emanuelsson H, et al. (2009) Ticagrelor versus clopidogrel in patients with acute coronary syndromes. N Engl J Med 361: 1045-1057.

5. Gaglia MA Jr, Waksman R (2011) Overview of the 2010 Food and Drug Administration Cardiovascular and Renal Drugs Advisory Committee meeting regarding ticagrelor. Circulation 123: 451-456.
6. Cannon CP, Harrington RA, James S, Ardissino D, Becker RC, et al. (2010) Comparison of ticagrelor with clopidogrel in patients with a planned invasive strategy for acute coronary syndromes (PLATO): a randomised double-blind study. Lancet 375: 283-293.

7. Held C, Asenblad N, Bassand JP, Becker RC, Cannon CP, et al. (2011) Ticagrelor versus clopidogrel in patients with acute coronary syndromes undergoing coronary artery bypass surgery: results from the PLATO (Platelet Inhibition and Patient Outcomes) trial. J Am Coll Cardiol 57: 672-684.

8. James S, Budaj A, Aylward P, Buck KK, Cannon CP, et al. (2010) Ticagrelor versus clopidogrel in acute coronary syndromes in relation to renal function: results from the Platelet Inhibition and Patient Outcomes (PLATO) trial. Circulation 122: 1056-1067.

9. Gurbel PA, Bliden KP, Butler K, Antonino MJ, Wei C, et al. (2010) Response to ticagrelor in clopidogrel nonresponders and responders and effect of switching therapies: the RESPOND study. Circulation 121: 1188-1199.

10. James S, Angiolillo DJ, Cornel JH, Erlinge D, Husted S, et al. (2010) Ticagrelor vs. clopidogrel in patients with acute coronary syndromes and diabetes: a substudy from the PLATelet inhibition and patient Outcomes (PLATO) trial. Eur Heart J 31: 3006-3016.

11. Husted S, James S, Becker RC, Horrow J, Katus H, et al. (2012) Ticagrelor versus clopidogrel in elderly patients with acute coronary syndromes: a substudy from the prospective randomized PLATelet inhibition and patient Outcomes (PLATO) trial. Circ Cardiovasc Qual Outcomes 5: 680-688. 